\title{
Gökkuşağı Alabalığı (Oncorhynchus mykiss) Yavrularında Görülen Gaz Kabarcığı Hastalığı ve Tedavisi Üzerine Bir Araştırma
}

\author{
Fikri BALTA $^{1^{*}} \quad$ Zeynep DENGIZZ BALTA ${ }^{2}$ \\ ${ }^{I}$ Recep Tayyip Erdoğan Üniversitesi, Su Ürünleri Fakültesi, Su ürünleri Yetiștiriciliği Böl. Hastalık ABD/RİZE \\ ${ }^{2}$ Recep Tayyip Erdoğan Üniversitesi, Fen Bilimleri Enstitüsü, Su Ürünleri Anabilim Dall /RİZE
}

Atıf yapmak için: Balta, F. \& Dengiz Balta, Z. (2020). Juvenil Gökkuşağı Alabalıklarında (Oncorhynchus mykiss) görülen Gaz Kabarcığı Hastalı̆̆ı ve Tedavisi. Anadolu Çev. ve Hay. Dergisi, 5(1), 100-105.

How to cite: Balta, F. \& Dengiz Balta, Z.. (2020). Gas Bubble Disease and Treatment Observed in Juvenile Rainbow Trouts (Oncorhynchus mykiss). J. Anatolian Env. and Anim. Sciences, 5(1), 100-105.

*iD: https://orcid.org/0000-0002-1823-5823

(iD) https://orcid.org/0000-0002-7795-828X

\section{*Sorumlu yazarın:}

Fikri BALTA

Recep Tayyip Erdoğan Üniversitesi, Su Ürünleri

Fakültesi, Zihni Deri.n Yerleşkesi, Fener Mah. 5310

/ Rize, Türkiye.

\: fikri.balta@erdogan.edu.tr

Cep telefonu : +90 (532) 4276489
Öz: Doğu Karadeniz Bölgesindeki 12 farklı gökkuşağı alabalığı (Oncorhynchus mykiss) kuluçkahanesindeki yavru balıklarda gaz kabarcığı hastalığı vakasına rastlanıldı. Yapılan araştırma sonuçlarına göre balıkların sularının yüksek ve uzak bir yerden kapalı boru içinde geldiği tespit edildi. Suyun boruyu tam olarak doldurmadığı ve direkt balık havuzlarına akıtıldığ belirlendi. Yavru balıkların bulunduğu havuzlarda çözünmüş oksijen $\left(\mathrm{O}_{2}\right)$ miktarı 12,6-14,5 mg/l olduğu, saturasyonu \%115,2-130,5 ve su sıcaklığ $18,2-9,7^{\circ} \mathrm{C}$ olarak ölçüldü. Sudaki erimiş gazlar uçurularak gaz saturasyonunun \%100'ün altına düşürülmesi sağlandı ve gaz kabarcığı problemi çözüldü. Süpersaturasyon vakalarında, sudaki çözünmüss gaz giderildiğinde gökkuşağı alabalık yavrularında \%10-30 aralığında bir ölüm meydana geldiği tespit edildi. Suyun süpersaturasyon durumu çözülmediği takdirde ise ölüm oranı \% 100 'e yaklaştığı görüldü.

Anahtar kelimeler: Gaz doygunluğu, gaz kabarcığı hastalığı, kuluçkahane yönetimi, Oncorhynchus mykiss.

\section{A Study on Gas Bubble Disease and Treatment Observed in Rainbow Trout (Oncorhynchus mykiss) Fry}

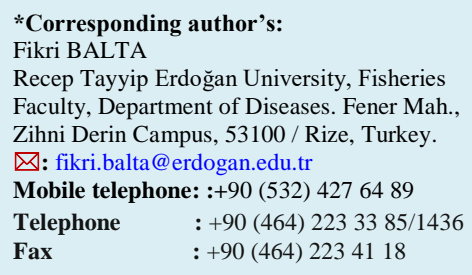

\begin{abstract}
Gas bubble disease was observed in juvenile fish in 12 different rainbow trout (Oncorhynchus mykiss) hatcheries in the Eastern Black Sea Region. According to the results of the research, it was determined that the waters of the fish came from a high and remote place in a closed pipe. And also, result of the study showed that the water in the pipe was not filling up the pipe and was observed the water was drained directly in the fish pond from the pipe. Dissolved oxygen, oxygen saturation and water temperature values in fry fish pond were determined as 12.6$14.5 \mathrm{mg} / \mathrm{l}, 115.2-130.5 \%$ and $8.2-9.7^{\circ} \mathrm{C}$ respectively. Molten gases in the water were blown away, allowing the gas saturation to fall below $100 \%$, and the gas bubble problem was solved. As a result, the gas bubble problem was solved. In the cases of supersaturation, it was found that when the dissolved gas in the water was removed, a death of 10-30\% occurred in rainbow trout fry. If the supersaturation status of the water is not resolved, the mortality rate has reached $100 \%$ in rainbow trout fry.
\end{abstract}

Keywords: Gas bubble disease, gas saturation, hatchery management, Oncorhynchus mykiss.

\section{GÍRIŞ}

Gaz kabarcığı hastalığg balıklarda önemli morbidite ve mortaliteye neden olan ve sudaki toplam çözünmüş gazın aşırı doymuş seviyeleri tarafından oluşturulduğu çeşitli literatürde bildirilmektedir. Doğal ve kültür balıklarında bu hastalıkla ilişkili bozukluklara ait çok sayıda yayın bulunduğu rapor edilmiştir (Grahn vd., 2007; Weitkamp \& Katz, 1980). Aşırı doymuş kuyu veya kaynak suyunun kullanıldığı bazı kuluçkahanelerde yüksek azot basınçları 
gaz kabarcığı hastalığına neden olmasının yanı sıra, atmosferik hava ile havalandırmanın da ciddi aşırı gaz doygunluğuna neden olabileceği de bildirilmiştir (Colt \& Westers, 1986). Çin'de üç büyük baraj türbinlerinden dökülen suyun süpersature (\%120-\%140) olması nedeni ile doğal ortamlardaki mersin balıklarında ölüm meydana geldiği rapor edilmiştir (Liu vd., 2019). Çinde yukarı Yangtze nehri üzerinde inşa edilen yüksek barajlarındaki türbün deşarjı tarafından çıkış suyunun aşırı süpersature olduğu ve balıklarda gaz kabarçığı hastalığının oluşmasına neden olduğu rapor edilmiştir (Wang vd., 2015) Ayrıca, yüksek barajlardan dökülen suyun deşarjının süper doygunluğu (\%140-150) nedeni ile balıkların gaz kabarcığ hastalığından kolayca etkilendiği bildirilmiştir (Shen vd., 2019). Balıklardaki lezyonlar kan damarları ve dokuların içinde gaz baloncuklarının birikimi ile şekillenmektedir. Hastalığın nedeni genellikle kaynak/yer altı suyunda özellikle azotun artan kısmı bir basıncı, oksijen ya da azot gazının aşırı doygunluğu hastalığa neden olduğu, ancak, toplam çözünmüş gazın bireysel gazlardan veya değişen gaz kombine oranından daha önemli olduğu rapor edilmektedir. Suda solunum yapan balığın kandaki gaz basıncı sudaki gaz basıncı ile aynı seviyededir. Eğer bu basınç oksijenin çok kullanılmasından dolayı düşmüşse ve suyun sıcaklığında düşme varsa ya da içindeki gaz miktarı düşük olan yeni bir su eklenmişse bu durumda kanda erimiş sıvı halinde bulunan azot gazı gaz formuna dönüşerek kan damarlarında kabarcıkların oluşumuna neden olduğu bildirilmiştir. Balıklar çözünmüş oksijeni \%300'e kadar dayanabilmesine karşın, aşırı doyma nitrojen kaynaklı olduğunda ciddi ve ağır problemlere sebep olduğu bildirilmektedir (Pennell \& Mclean, 1996; Timur \& Timur, 2003). Hastalığa amfibiler ve sucul omurgasızlar yanı sıra bütün balık türlerin duyarlı olduğu, balık türlerinde ve yaş gruplarında hassasiyet farklı olduğu; yavrular serbest yüzene kadar çok hassas olduğu bildirilmektedir. Hastalık toplam gaz basıncı yaklaşık \%103 olduğunda kronik form ve \%110-115 üzerinde akut form meydana geldiği rapor edilmektedir. Kronik formda, özellikle yavru balıkların semptom göstermeksizin yavaş yavaş öldüğü ve ölümün $\% 5$ seviyelerde olduğu bildirilmiştir. Akut formun klinik semptomları; oryantasyon (uyum) bozukluğu, deri altı amfizem, emboli, çoğunlukla sadece tek taraflı ekzofthalmus, deride kararma olan balıkların su yüzeyine yakın yüzdüğü, kanamalar ve \%100 ulaşan yüksek ölüm meydana geldiği rapor edilmiştir. Toplam gaz basıncındaki artışa paralel olarak balık kayıpların da arttığı ve bazı bateriyel hastalıklarda olduğu gibi büyük ekonomik kayıplara neden olduğu tespit edilmiştir (Balta \& Dengiz Balta, 2019). Kronik formdaki ölümler, genellikle, amfimatöz dokunun sekunder enfeksiyonları tarafından artış gösterdiği bildirilmiştir. Teknik işlemler, örneğin; su pompalama, su 1sıtma veya 11 k su ile soğuk suyu karıştırma toplam gaz basıncının artmasına neden olduğu bildirilmektedir. Gaz kabarcığı hastalığının ana sebebi nitrojen $\left(\mathrm{N}_{2}\right)$ olmakla birlikte karbondioksit $\left(\mathrm{CO}_{2}\right)$ ve nadiren bazı gazlar (argon) daha az önemli olduğu rapor edilmektedir. Çözünmüş oksijen (DO) konsantrasyon, akan suyun derecesine ve oksijen çözünürlüğüne bağlı olduğu rapor edilmektedir. Oksijen çözünürlüğü sıcaklık ve tuzlulukla azalırken barometrik basınçla arttığı bildirilmektedir (Colt, 1984; Hitchman, 1978). Deniz seviyesinde ( $\mathrm{BP}=760 \mathrm{~mm} \mathrm{Hg}) 10^{\circ} \mathrm{C}$ 'de tatl suda atmosfer basincı ile dengede (\%100 doygunluk) $11,3 \mathrm{mg} / \mathrm{l}$ bir oksijen konsantrasyonuna sahip olduğu bildirilmiştir. Eğer doygunluk \%95 ise bu durumda oksijen 0,95 x 11,3 = 10,7 $\mathrm{mg} / \mathrm{l}$ olarak hesaplanırken, eğer doygunluk \%15,0 ise bu durumda da 1.5 x 11,3=17,0 mg/l olarak hesaplandığ 1 bildirilmiştir.

Bu çalışmada, gaz kabarcığ suyun fiziksel ve kimyasal özellikleri klasik yöntem ve oksijen metre ile ölçülerek belirlenmiştir. Sulardaki süpersaturasyonun önlenmesi için çeşitli yöntemlere başvurulmuştur. Kaynak suyunun su geliş sisteminde değişiklikler yapılarak toplam gaz doygunluğunun \%100'ün altına düşürdüğünde hastalık semptomlarının ortadan kalktığı, ölümlerin yavaş yavaş azaldığı ve balıkların normal davranışlarına geri döndüğü tespit edilmiştir.

\section{MATERYAL VE METOT}

Materyal: Bu çalışma, 1999-2018 yılları arasında Doğu Karadeniz bölgesindeki 4 farklı ildeki gökkuşağı alabalık çiftliklerinden Fakültemiz laboratuvarına getirilen yavru balıklarda gaz kabarcı ğı hastalık semptomları tespit edildi. Trabzon (5), Rize (5), Artvin (1) ve Gümüşhane (1) olmak üzere toplam 12 değişik çiftliklerde hastalık vakasına rastlanıldı. Özellikle, kış ve bahar aylarında gökkuşağı alabalık çiftliklerinin kuluçkahanelerdeki yavru havuzlarında yumurta kesesini yeni bitirmiş $(0,2-0,3 \mathrm{~g})$ ve yavru balıklarda (1-2 g) şiddetli ölümlere rastlanıldı.

Metot: Gaz kabarcığı hastalık belirtileri gösteren çiftliklerin su kaynakları ve yavru balıklar yerinde incelendi. Kaynak suyunu balık çiftliklerine kapalı borularla yüksek ve uzak mesafelerden getirildiği görüldü. Kuluçkahaneye akıtılan kaynak sularından su örnekleri alınarak laboratuvara getirildi ve klasik yöntemlerle kimyasal analizleri yapıldı. Kaynak suyunun sıcaklığı, pH'sı, serbest oksijen seviyesi, oksijen doygunluğu ve basınc1 (hektopaskal=hpa) oksijen metre (Hach HQ40d multi) ile yerinde ölçüdü (Şekil 1). Kuluçkahanelere gelen kaynak suyunun mesafesi, getiriliş şekli ve boru çapları özellikleri incelendi.

Balıkların muayenesi: Balık çiftliklerindeki yavru tanklarındaki balıkların sırt üstü dönmüş ve karında gaz kabarcığı semptomu gösteren balıklarından 10`ar adet balık alındı (Şekil 2). Solungaç lamelleri mikroskop altında gaz yönünden muayene edildi. Balıkların bağırsak içerinden 
alınan dışkı örnekleri, solungaç lamellerinden ve deri yüzeyinden alınan kazıntı örnekleri parazit yönünden mikroskobik muayenesi yapıldı. Hastalıklı balıkların böbrek ve dalaklarından Triptik Soy Agar (TSA)'a, Triptik Soy Broth (TSB)'a ve Anacker Ordal Agar (AOA) ve Anacker Ordal Broth'a ekimler yapıldı. Besi yerleri soğutmalı etüvde $20 \pm 1^{\circ} \mathrm{C}$ 'de inkübasyona birakıldı.
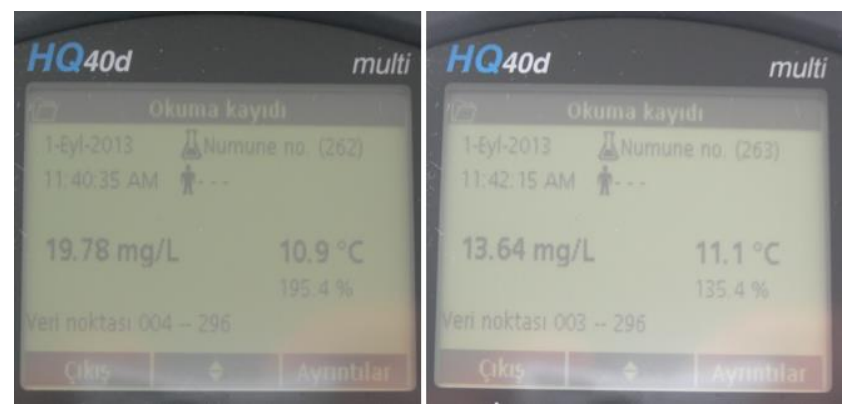

Şekil 1. Oksijen metre (Hach Lange HQ40d multimetre) ile havuz girişinde kaynak suyunun ölçüm sonuçları.

Figure 1. Measurement results of spring water at the pool entrance with oxygen meter (Hach Lange HQ40d multimeter).

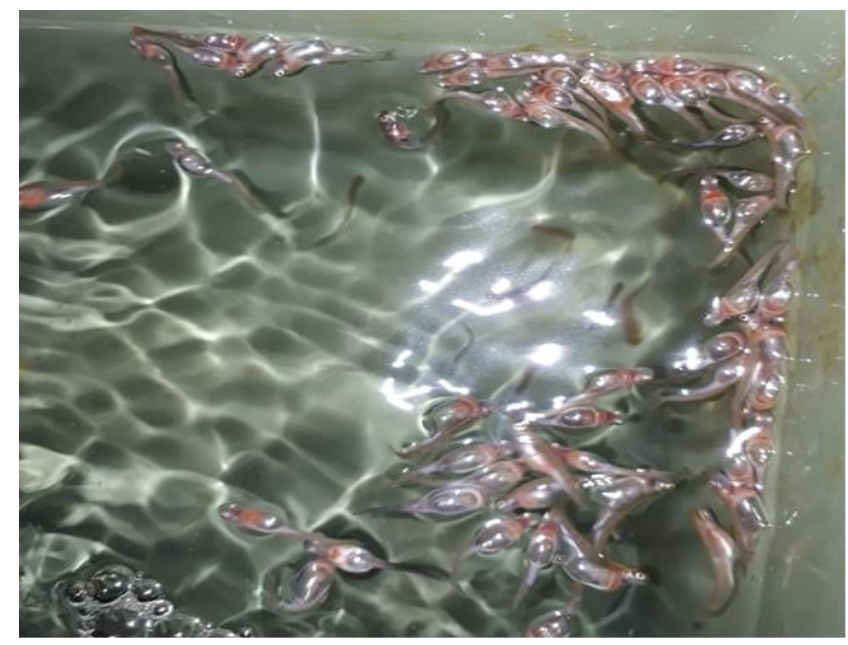

Şekil 1. Fiberglass tanklarda gaz kabarcığı hastalık semptomları gösteren yavru balıkların görünümü (Orijinal).

Figure 1. The appearance of juvenile fish showing symptoms of gas bubbles disease in fiberglass tanks (Original).

\section{BULGULAR}

Hastallk Semptomlarl: Balık çiftliklerinin kuluçkahanelerindeki havuzlarda, yavru balıklarının su yüzeyinde sırt üstü ters bir şekilde durdukları, karın altı şişkin olduğu, yavru balıkların yem almadığı ve balık ölümlerinin olduğu tespit edildi. Gökkuşağı alabalık yavrularında hastalık vakarlında yapılan ilk muayenelerde kuluçka havuzlarındaki yavru balıkların su yüzeyinde sırt üstü dönmüş bir şekilde su yüzeyinde bir araya toplandığı, halsiz oldukları, yem alamadıkları ve balıklara yaklaşılınca su dibine kaçamadıkları gözlendi. Yem kesesini yeni bitirmiş veya 1-2 g'lık yavru balıkların karın altındaki derinin gazla dolu şeffaf balon şeklinde şişkin olduğu gözlendi. Balıkların bazılarında renkte kararma belirlendi.
Hasta balıklara ait resimler Şekil 2'de verildi. Tanklardaki balıklarda morbitidenin \%100 olduğu görüldü. Yavru ölümlerin gün geçtikçe artı̆̆ı ve saturasyonun düzeltilmediği takdirde ölümlerin \%100 yaklaştı̆̆ tespit edildi.

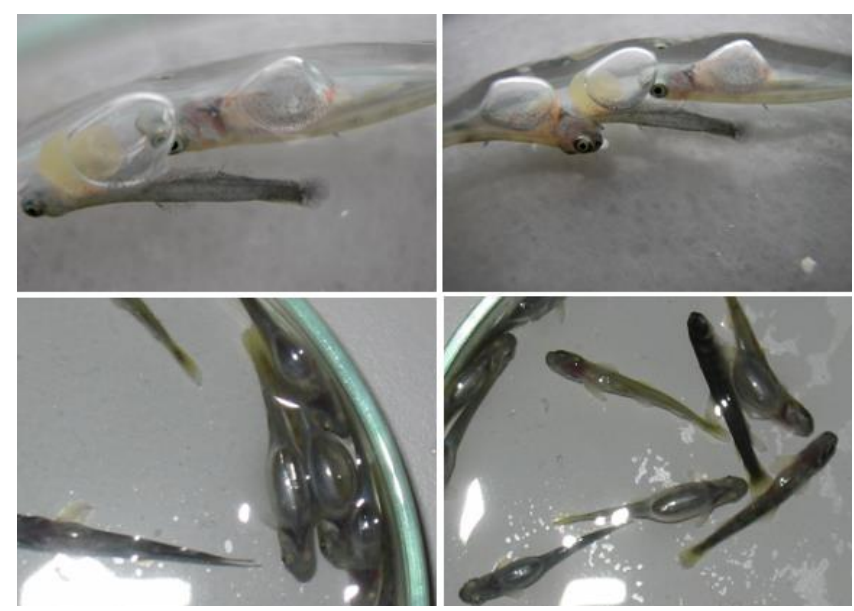

Şekil 2. Gaz kabarcığı hastalık semptomları gösteren yavru balıkların görünümü (Orjinal).

Figure 1. The appearance of juvenile fish with symptoms of gas bubbles disease (Original).

Suyun fiziksel ve kimyasal özellikleri: Karadeniz bölgesindeki balık çiftlikleri genellikle engebeli ve dik arazilere kurulmuş olması ve kaynak sularından uzak mesafelerden getirilmesi, kaynak suyunun gözesi ile kuluçkahane arasında kot farklı bulunduğu belirlendi. Balık çiftliği kuluçkahanelerine gelen kaynak suları genellikle kapalı plastik borularla (50-75 mm çapl1) uzak mesafelerden $(0,5 \mathrm{~km}-5 \mathrm{~km})$ getirildiği, arazinin orman ve zeminin taşlık olması nedeniyle toprağa gömülmediği yapılan incelemelerde tespit edildi. Suyun kuluçkahane seviyesinden çok daha yüksek bir yerden (yaklaşık 30-50 m arasında) geldiği, suyun boruyu tam olarak dolduramadığı ve hava emdiği tespit edildi. Ayrıca, boruların ek yerlerinin iyi yapıştırılmamış olması nedeni ile ek yerlerinden hava aldığı belirlendi. Kaynak sularının tazyikli, beyazımsı ve bazen suyun kesik kesik aktığı görüldü. Bazı üreticilerin $10^{\circ} \mathrm{C}$ 'deki kaynak suyunun yetersizliğinde $4^{\circ} \mathrm{C}$ 'deki dere suyu ile karıştırdıklarında bu olayın daha şiddetli oluştuğunu bildirdiler. Üreticilerin bazıları bu durumun kar sularının erimesinden kaynaklandığını ileri sürmüşlerdir. $\mathrm{Bu}$ durumdaki suyun yavru havuzlarına tazyikli olarak beyazımsı renkte aktığı görüldü. Yapılan ölçümlerde suya ait fiziksel ve kimyasal değerler Tablo 1'de verildi. Oksijen metre ile 2 nolu çiftlikte $9,7^{\circ} \mathrm{C}$ 'deki su sicaklığında en düşük saturasyon \%114 ve $11,72 \mathrm{mg} / 1 \mathrm{O}_{2}$ ölçülmasine karşın 9 nolu çiftlikte $10,9^{\circ} \mathrm{C}$ 'deki su sıcaklığında en yüksek saturasyon \%195,4 ve 19,78 mg/l O ölçülerek kayıt edildi ve Tablo 2 'de verildi. Uzak mesafelerden gelen kaynak sularına ait geliş şeması Şekil 3'de şematize edildi.

Ballkların muayenesi: Gaz kabarcığı belirtisi gösteren yavru balıkların solungaç lamellerinin mikroskop 
altındaki muayenesinde gaz kabarcığına rastlanılmadı. Ayrıca, balıkların deri, solungaç kazıntıları ve bağırsak içeriğinin mikroskobik muayenesinde bakteriyel ve paraziter hastalık etkenine rastlanılmadı. Hastalıklı balıkların böbrek ve dalaklarından yapılan ekimler 7 gün süresince takip edildi. TSA, TSB, AOA ve AOB'da herhangi bir bakteriyel etkene rastlanılmadi.

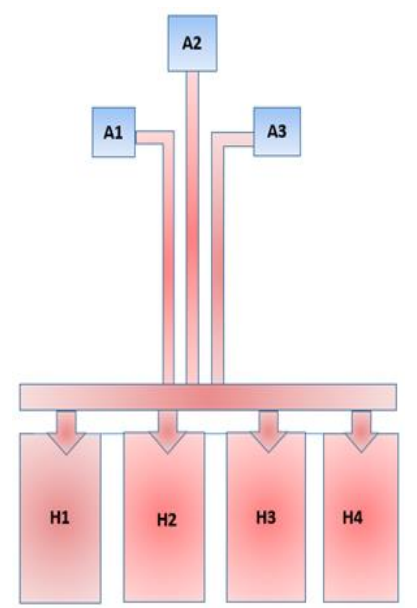

Şekil 3. Kaynak suyunun akış şeması (A: Suyun kaynağı, H: Yavru havuzlar1).

Figure 3. Flow chart of spring water (A: Source of water, H: Juvenile pools).

Tablo 1. Kaynak suyuna ait fiziksel ve kimyasal özellikler.

Table 1. Physical and chemical properties of spring water.

\begin{tabular}{|c|c|c|c|c|c|c|c|c|c|c|c|c|}
\hline \multirow{2}{*}{$\begin{array}{l}\text { Kaynak suyuna ait } \\
\text { parametreler }\end{array}$} & \multicolumn{12}{|c|}{ Gaz kabarcığı hastalığı vakası tespit edilen çiftlikler } \\
\hline & 1 & 2 & 3 & 4 & 5 & 6 & 7 & 8 & 9 & 10 & 11 & 12 \\
\hline Mesafe $(\mathrm{km})$ & 2,5 & 1,3 & 1,2 & 2,8 & 3,1 & 3,4 & 3,2 & 3,5 & 3,8 & 2,7 & 1,2 & 2,9 \\
\hline Yükseklik (m) & 20 & 12 & 13 & 25 & 15 & 13 & 30 & 30 & 40 & 25 & 10 & 17 \\
\hline Sicaklık $\left({ }^{\circ} \mathrm{C}\right)$ & 7,2 & 7,5 & 8,2 & 7,8 & 8,8 & 9,5 & 8,9 & 9,7 & 14,4 & 12 & 10 & 20,9 \\
\hline $\mathrm{pH}$ & 7,15 & 7,04 & 7,04 & 7,07 & 7,15 & 7,11 & 7,05 & 7,07 & 7,04 & 7,10 & 7,08 & 7,12 \\
\hline $\mathrm{O}_{2}(\mathrm{mg} / \mathrm{l})$ & 9,88 & 11,6 & 11,4 & 11,9 & 11,85 & 12,1 & 11,9 & 12,2 & 9,99 & 10,64 & 10,96 & 10,68 \\
\hline $\mathrm{CO}_{3}$ & 0 & 75 & 69,5 & 40,3 & 61 & 0 & 58,2 & 67,1 & 68,04 & 0 & 0 & 0 \\
\hline $\mathrm{HCO}_{3}$ & 52,5 & 46,9 & 40,2 & 43,6 & 45,40 & 0 & 0 & 44,6 & 0 & 43,7 & 50,2 & 0 \\
\hline $\mathrm{CO}_{2}$ & 1,5 & 0,6 & 0,5 & 1,1 & 1,2 & 0 & 0 & 1,2 & 0 & 0,9 & 1,3 & 0,6 \\
\hline Alkalinite & 33 & 42,5 & 53 & 32 & 45,5 & 48,5 & 30,6 & 36,4 & 46,6 & 49,1 & 46,6 & 38,5 \\
\hline Nitrit $(\mu \mathrm{g} / \mathrm{l})$ & 0 & 0 & 0 & 2 & 0 & 0 & 0 & 0 & 0 & 0 & 0 & 0 \\
\hline Nitrat (mg/l) & 1,2 & 0 & 0 & 0 & 0,8 & 0 & 0 & 0 & 0 & 0 & 0 & 0,4 \\
\hline Amonyak & 0 & 0 & 0 & 0 & 0 & 0 & 0 & 0 & 0 & 0 & 0 & 0 \\
\hline $\mathrm{Ca}$ & 1,0 & 1,5 & 1,9 & 2,4 & 1,7 & 6,8 & 8,3 & 12 & 7,1 & 2,3 & 3,9 & 5,6 \\
\hline $\mathrm{Mg}$ & 1,4 & 2,0 & 2,3 & 3,4 & 2,3 & 3,9 & 4,2 & 3,8 & 4,8 & 3,1 & 2,5 & 3,3 \\
\hline $\mathrm{OH}$ & 0 & 0 & 0 & 0 & 0 & 0 & 0 & 0 & 0 & 0 & 0 & 0 \\
\hline Toplam sertlik & 23 & 14 & 20 & 23 & 34 & 23 & 14 & 26 & 30 & 36 & 28 & 18 \\
\hline
\end{tabular}

Tablo 2. Hastalık vakası çıkan çiftliklerde yavru havuzlarının giriş suyunun oksijen değerleri.

Table 2. Oxygen values of the inlet water of juvenile pools in farms with disease cases.

\begin{tabular}{|c|c|c|c|c|}
\hline Çiftlikler & Serbest $\mathrm{O}_{2}$ & $\mathrm{O}_{2}$ Doygunluğu & Sicaklik & Basınç \\
\hline 1 & $14,58 \mathrm{mg} / \mathrm{l}$ & $\% 125$ & $8,9^{\circ} \mathrm{C}$ & $880 \mathrm{hpa}$ \\
\hline 2 & $11,72 \mathrm{mg} / \mathrm{l}$ & $\% 114$ & $9,7^{\circ} \mathrm{C}$ & 886 hpa \\
\hline 3 & $12,62 \mathrm{mg} / 1$ & $\% 127,1$ & $7,5^{\circ} \mathrm{C}$ & 865 hpa \\
\hline 4 & $15,05 \mathrm{mg} / \mathrm{l}$ & $\% 155,6$ & $8,2^{\circ} \mathrm{C}$ & $930 \mathrm{hpa}$ \\
\hline 5 & $13,64 \mathrm{mg} / 1$ & $\% 135,4$ & $9,5^{\circ} \mathrm{C}$ & $945 \mathrm{hpa}$ \\
\hline 6 & $13,64 \mathrm{mg} / 1$ & $\% 135,4$ & $8,6^{\circ} \mathrm{C}$ & $956 \mathrm{hpa}$ \\
\hline 7 & $18,62 \mathrm{mg} / \mathrm{l}$ & $\% 186,8$ & $9,8^{\circ} \mathrm{C}$ & 930 hpa \\
\hline 8 & $18,01 \mathrm{mg} / 1$ & $\% 180,5$ & $10,6^{\circ} \mathrm{C}$ & 930 hpa \\
\hline 9 & $19,78 \mathrm{mg} / \mathrm{l}$ & $\% 195,4$ & $10.9^{\circ} \mathrm{C}$ & $930 \mathrm{hpa}$ \\
\hline 10 & $15.61 \mathrm{mg} / \mathrm{l}$ & $\% 156,1$ & $11,5^{\circ} \mathrm{C}$ & 918 hpa \\
\hline 11 & $12,90 \mathrm{mg} / 1$ & $\% 118,4$ & $11,9^{\circ} \mathrm{C}$ & $925 \mathrm{hpa}$ \\
\hline 12 & $13,88 \mathrm{mg} / \mathrm{l}$ & $\% 139,1$ & $9,9^{\circ} \mathrm{C}$ & $969 \mathrm{hpa}$ \\
\hline
\end{tabular}




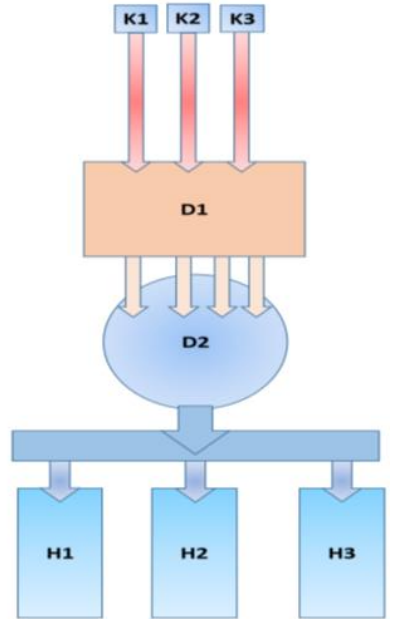

Şekil 4. Suyun doygunluğunun giderilmesi (K: Kaynak, D: Dinlendirme havuzu, H: Yavru havuzları)

Figure 4. The way of saturation removal of water (K: Source, D: Collection pool, H: Juvenil pools).

\section{SONUÇ VE TARTIŞMA}

Çözünmüş oksijen miktarı sudaki yaşamı sürdürmek için gereklidir. Bazı durumlarda balık refahı için en önemli sınırlayıcı faktörlerden biridir. Suda oksijenin tüketilmesi muhtemelen en sık görülen su kirliliği biçimlerinin genel bir sonucudur. Sudaki oksijen azlığına maruz kalan balıklar yem tüketmezler, su yüzeyine yakın yüzerler, hava için soluklanırlar (sazanlarda), su girişine toplanırlar, uyuşuk, tepkisiz, kaçma ve yakalama kabiliyetlerini kaybederler ve en sonunda boğularak ölürler. Ancak, sudaki çözünmüş fazla oksijen miktarları (aşırı doygunluk) tarafından balıklarda meydana gelen hasara nadiren rastlanılmaktadır. Suyun oksijen doygunluk kritik değeri \%250-300 seviyelerinde olduğu bildirilmiştir. Oksijen aşırı doygunluğuna yanıt olarak, etkilenen balıkların solungaçları belirgin şekilde açık kırmızı bir renge ve solungaç lamellerin uçlarının yıpranmış olduğu rapor edilmiştir. Bu durumdaki balıkların sekunder mantar enfeksiyonlarından muzdarip oldukları ve bazılarının da öldüğü bildirilmiştir (Svobodova vd., 1993).

Suudi Arabistan'daki bir araştırmada dört farklı balık çiftliğinde gaz kabarcığı hastalığı salgınının görüldüğü, tüm vakalarda toplam su gazı basıncı \%111,2 ve \%113,4 arasında değişdiği, oksijen normal değerlerde iken azot gazının aşırı doymuş olduğu bildirilmiştir. İlk iki vakanın tuzlu suda yetiștirilen 52,5 g'llk tilapiayalar (Oreochromis spilurus)'da gerçekleştiği; vakalardan birinde stokun yaklaşık \%50'sini etkiledi ve yaklaşık \%30'luk bir ölümle sebep olduğu ve ikinci vakada ise popülasyonun yaklaşık \%25'ini etkilediği ve \%5'nin öldüğü bildirilirken, 3. vakanın acı sudaki (\%0,5 tuzluluk) $270 \mathrm{~g}$ ağırlığındaki yetişkin tilapialar (Oreochromis niloticus) arasında salgına neden olduğu ve yaklaşık \%40 ölüme neden olduğu, 4. salgın ise üç aylık 15 g'lık orfoz
(Epinephelus fuscoguttatus) balıkları arasında meydana geldiği ve \%10'luk ölüm oranı ile sonuçlandığı bildirilmiştir. Kaynak suyunun sıçratılarak veya daha düşük gaz basıncı olan bir su kaynağı kullanarak, gaz basıncını düşürülmesi ile salgınların hafifletildiği bildirilmiştir (Saeed \& Al-Thobaiti, 1997). Bu çalışmada, kuluçkahane suyunda süpersaturasyon vakalarında yavru gökkuşağı alabalıklarda \%100'lük morbitide ve saturasyon problemi çözülmediği durumlarda \%100'e yakın mortalite görülmesine karşın saturasyonun giderilmesi durumunda \%10-30’luk mortalitenin meydana geldiği tespit edildi. Artezyen suyu kullanılarak kültürü yapılan Nil Tilapyası ve Melez Kirmızı Tilapya (Cichlidae, Oreochromis spp.)'da görülen gaz kabarcığı hastalığında balıkların Ağustos ayında \%50'sinin etkilediği ve çoğunun öldüğü, aynı araştırmada tüm balıkların Aralık ayında etkilendiği ve hepsi öldüğü rapor edilmiştir (Midilli vd., 2019). Karadeniz Bölgesindeki alabalı üretiminin sürdürebilirliğini etkileyen süpersaturasyon toplu ölümlere (\%80) nedeni ile önemli ekonomik kayıplara neden olduğu tespit edilmiştir (Balta \& Dengiz Balta, 2019).

Suyun aşırı doygun hale gelmesinin dört yolunun olduğu bildirilmiştir. (1); $\mathrm{Su}$, aşırı doygun hale gazın normalde havada bulunandan daha yüksek bir yüzdesini içeren çözünmüş bir gaz karışımından ileri geldiği ve sadece deneysel koşullar altında bu mekanizmanın etkili olduğu için büyük bir önem taşımadığı ileri sürülmüştür. (2); Su, atmosferden daha yüksek bir basınç altında çözülmüş gaz içerdiği ve aşırı doygunluk vakalarının çoğunda bu mekanizmanın etkili olduğu bildirilmiştir. Örneğin; hidroelektrik santrallerin çalışma sisteminde hava enjeksiyonu yoluyla; su ve hava su kanalında karıştırılır ve kanal sistemi ile çıkışa taşındığı bildirilmiştir. Balık çiftliklerinde yeraltı suyu kullanımından veya suyun pompalanmasından da kaynaklandığı belirtilmiştir. (3); Su, ortam sıcaklığından daha düşük bir sıcaklıkta çözünmüş gaz içerdiği durumlarda aşırı doygun hale geldiği ileri sürülmüştür. Su balık kültürü için 1sıtıldığında, enerji üreten tesislerde ve doğal suların jeotermal 1sıtmasında suyun soğutulması sırasında aşırı doygunluğa neden olur, çünkü artan su sıcaklığ́ ile gazların çözünürlüğü azaldığ1 bildirilmiştir. Sudaki konsantrasyonları belirli bir sıcaklıktaki çözünürlüklerinden daha yüksekse, suyun 1sıtılması gazların salınmasına neden olduğu bildirilmiştir. (4); Farklı sıcaklıklarda iki doymuş su kütlesi karıştırıldığında aşırı doygunluğa neden olabildiği, fakat çoğu zaman gaz kabarcığı hastalığının meydana gelmesine neden olacak kadar yüksek seviyelerde doygunluk üretmediği rapor edilmiştir (Lindroth, 1957). Büyük miktarda su kullanan kapalı akan sitemlerde, su bir yoğunlaşmış sütun (dar helozonik sütunlar) gaz giderci kullanarak aşırı gazların çıkartılabildiği rapor edilmiştir. Pasif gaz gidericilerin gaz konsantrasyonunu \%100'e 
indirmek için kullanıldığı, fakat vakumlu gaz giderme sistemlerinin daha büyük bir güven sınırı sağladığı bildirilmiştir (Colt, 1986).

Gaz kabarcı̆̆ 1 hastalığının tedavisinde ilk yapılması gerekli işlemin su kaynağındaki aşırı gazın elimine (uzaklaştırılması) edilmesi gerektiği ve süpersature olan suyun direkt yavru balık havuzlarına verilmesi engellenmiştir. Bu amaçla, suyun girişindeki borunun hava yapmayacak boyutlarda olması sağlanmıştır. Süpersature olmuş su bir engele çarptırılarak birinci depoya akışı sağlanmış ve havuzun üzerine hava bacaları yerleştilerek gazın dışarı atılması sağlanmışıı. Bu havuzdaki suyu 2. depoya aktarırken kanal sistemine suyun gazını uzaklaştırmaya yardımcı olmak amaçıyla kanal içine taş engeller konulmuş, kanalın üzeri kapatılmış ve kanal boyunca gaz bacaları bırakılmıştır. Başka bir çiftlikte uzak mesafeden getirilen ve hava emerek süpersatüre olan su önce bir fiberglas tanka çarptırılarak veya fiskiye tarzında dökülerek gazın çıkarılması sağlanmıştır. Birinci dinlenme tankından suyun taşarak akması ve su akışının altına tahta yerleştirilerek suyun dağılarak içindeki gazın uçurulması amaçlanmıştır. Böylece, sudaki gazın uzaklaştırılması ve 2 . depodaki suyun saturasyununun $\% 100$ altına düşürülmesi sağlandıktan sonra yavru tanklarına su verildiğinde birkaç gün sonra problemin çözüldüğü tespit edilmiştir.

$\mathrm{Bu}$ çalışma sonuçlarına göre kaynak sularının fiziko-kimyasal analiz sonuçları, balık çiftliğine sağlanan suyun çok iyi kalitede olduğunu göstermiştir. Kaynak suyu analizlerinde amonyağın olmaması ve çok düşük konsantrasyonlarda, nitratlar, nitritler, klorürler ve toplam fosfor değerleri (veya sınırının altındaki miktarlarda) ile birlikte, kanalizasyon veya tarımsal atık suları ile kontaminasyonun olmadığını da göstermektedir. Sürdürülebilir üretim için üreticilerin iyi bir gözlemci olmaları ve süpersature olan suyun zamanında tespit etmeleri gerekmektedir. Gökkuşağı alabalığı yavrularına süpersature olan suyun direkt verilmemesi, su değerlerinin mutlaka saturasyon yönünden ölçülmesi ve sudaki erimiş gazların uçurulması gerektiği sonucuna varılmıştır.

\section{KAYNAKLAR}

Balta, F. \& Dengiz Balta, Z. (2019). The isolation of Lactococcus garvieae from eyes of diseased rainbow trout (Oncorhynchus mykiss) with exopthalmia. Anatolian Env. and Anim. Sciences, 4(1), 27-33. DOI: $10.35229 /$ jaes.527258

Colt, J. \& Westers, H. (1982). Production of gas supersaturation by aeration. Transaction of the American Fisheries Society, 111(3), 342-360.

Colt, J. (1984). Computation of disolvedgas concentration in water as fuctions of temperature, sality and pressure. American Fisheries Society, Special publication no: $14,154 \mathrm{p}$.
Colt, J. (1986). Gas supersaturation-impact on the design and operation of aquatic systems. Aquacultural Engineering, 5, 49-85. DOI: 10.1016/01448609(86)90005-1.

Edsall, D.A. \& Smith, C.E. (1991). Oxygen-induced gas bubble disease in rainbow trout, Oncorhynchus mykiss (Walbaum). Aquaculture Research. 22(2), 135-140. DOI: 10.1111/j.13652109.1991.tb00503.x.

Grah, B.H., Sangste, C., Breaux, C., Stephe, C. \& Sandmeye, L. (2007). Case report: Clinical and pathologic manifestations of gas bubble disease in captive fish. Journal of Exotic Pet Medicine, 16(2), 104-112. DOI: 10.1053/j.jepm.2007.03.008.

Hitchman, M.L. (1978). Measurument of dissolved oxygen. Willey interscience; New York NY 255p.

Lindroth, A. (1957). Abiogenic gas supersaturation of river water. Archiv fur Hydrobiologie, 53, 589-597.

Liu, X., Li, N., Feng, C., Fu, C., Gong, Q., Lai, Ji., Jiang, Z., Yang, Y. \& Shi, H. (2019). Lethal effect of total dissolved gas-supersaturated water with suspended sediment on river sturgeon (Acipenser dabryanus). Scientific Reports. 9, 13373. DOI: 10.1038/s41598019-49800-y.

Midilli, S., Çoban, D., Güler, M. \& Küçük, S. (2019). Kültür koşullarında Nil Tilapyası ve Melez Kırmızı Tilapya (Cichlidae, Oreochromis spp.)'da görülen gaz kabarcığı hastalığı. Su Ürünleri Dergisi, 36(3), 285-291. DOI: 10.12714/egejfas.2019.36.3.09.

Pennell, W. \& McLean, W. E. (1996). Early rearing. In principles of salmonid culture, vol. 29 (eds. William, P. and Barton, B. A.), 365-465 pp. The Netherlands, Amsterdam, Elsevier.

Saeed, M. \& al-Thobaiti, S.A. (1997). Gas bubble disease in farmed fish in Saudi Arabia. Vet. Res., 140(26), 682684. DOI: $10.1136 / v r .140 .26 .682$.

Shen, X., Li, R., Hodges, B.R., Feng, J., Cai, H. \& Ma, X. (2019). Experiment and simulation of supersaturated total dissolved gas dissipation: Focus on the effect of confluence types. Water Research, 155, 320-332. DOI: 10.1016/j.watres.2019.02.056.

Svobodova, Z., Lloyd, R., Machova, J. \& Vykusova, B. (1993). Water quality and fish health (No. 35). EIFAC, Rome. 59pp.

Timur, G. \& Timmur, M. (2003). Ballk hastalıkları. İstanbul Üniversitesi, Su Ürünleri Fakültesi Yayınları No:5, Dilek Ofset, İstanbul, 588s.

Wang, Y., Li, K., Li, J., Li, R. \& Deng, Y. (2015). Tolerance and avoidance characteristics of Prenant's Schizothoracin Schizothorax prenanti to total dissolved gas supersaturated water. North American Journal of Fisheries Management 35(4), 827-834. DOI: 10.1080/02755947.2015.1052160.

Weitkamp, D.E. \& Katz, M. (1980). A Review of Dissolved Gas Supersaturation Literature. Transactions of the American Fisheries Society, 109, 659-70. 